\title{
ANALISIS PENGARUH PEMBAJAKAN DIGITAL DI KALANGAN MAHASISWA PADA KAMPUS GICI BUSINESS SCHOOL BATAM
}

\author{
Joko Setiawan ${ }^{1)}$ \\ ${ }^{1)}$ Program Studi Akuntansi, Akademi Akuntansi Permata Harapan \\ awwansetyawan@gmail.com
}

\begin{abstract}
Penelitian ini menggunakan attitude, perceived behavioral control, subjective norms, moral obligation dan past piracy behavioral untuk menganalisis intention terhadap digital piracy (software) dan intention terhadap behavior pada digital piracy software) di kalangan mahasiswa GICI Business School Batam. Metode pengumpulan data menggunakan kuesioner dengan jumlah akhir responden sebanyak 100 orang. Data yang diperoleh diuji dengan menggunakan perangkat lunak Statistical Package for the Social Sciences (SPSS) versi 20 untuk mengetahui pengaruh antara variabel-variabel attitude, perceived behavioral control, subjective norms, moral obligation dan past piracy behavior terhadap intention dan intention terhadap behavior pada digital piracy (software). Hasil penelitian menunjukkan bahwa attitude, perceived behavioral control, subjective norms, moral obligation dan past piracy behavior terhadap intention mempengaruhi intention dalam melakukan digital piracy (software).

Keywords:

attitude, perceived behavioral control, subjective norms, moral obligation, past piracy behavior, intention, behavior, digital piracy (software), SPSS 20.
\end{abstract}

\section{PENDAHULUAN}

Software piracy diartikan sebagai pembajakan yang ilegal, di mana sebuah organisasi mengembangkan software untuk mempermudah seseorang melakukan kegiatan kerja maupun tugas perkuliahan, tetapi selalu salah gunakan dengan menduplikasi software tersebut untuk menghindari biaya (Straub \& Collins, 1990).

Software piracy bukanlah hal yang baru, meskipun arus diakui bahwa internet telah memberikan kesempatan yang besar untuk pelanggaran hak cipta yang lebih besar. Pembajakan tersebar luas di Eropa. Eropa Timur dianggap sebagai salah satu pusat operasi terbesar untuk memproduksi dan mendistribusikan software piracy. Menurut Business Software Alliance (BSA), pada tahun 2000, tingkat pembajakan diperkirakan berkisar $88 \%$ di Rusia, 26\% di Denmark dan United Kingdom (Antonio, 2002).

Perusahaan perekaman music Recording Industry Association of America (RIAA) melaporkan bahwa dalam tahun 1999 hingga 2002 penjualan mengalami penurunan sebesar $31 \%$, hal ini disebabkan oleh pembajakan. Industri filem yang menjadi korban target pembajakan yaitu The Motion Picture Association of America (MPAA). Diperkirakan sebanyak 400,000-600,000 film di download lewat internet setiap hari (MPAA, 2003).
JURSIMA

Jurnal Sistem Informasi dan Manajemen 
Estimasi yang diperkirakan oleh MPAA mengalami kerugian sebesar 18,2 Bilion US Dolar dalam setahun disebabkan oleh pembajakan digital (Cronan \& Al-Rafee, 2008).

Di kawasan Asia, tingkat pembajakan ratarata meningkat satu poin menjadi $54 \%$ pada tahun ini. Namun demikian, tingkat pembajakan di enam negara Asia yang memiliki pertumbuhan ekonomi yang sehat menurun. Cina memimpin dengan tingkat penurunan empat poin yang diikuti oleh India, Singapura, dan Vietnam dengan penurunan dua poin. Ini terkait dengan kenaikan pasar PC di Cina dan India 2\% menjadi 29\% pada 2005 (Tempointeraktif, 2006).

Masalah pembajakan software telah menjadi fenomena dibanyak negara. Di Indonesia, menurut data terakhir yang dikeluarkan Business Software Alliance (BSA), tingkat pembajakan software mencapai angka 87\%. Perwakilan Business Software Alliance untuk Indonesia lebih dari satu software yang dipasang di komputer adalah software ilegal. Dengan demikian, pembajakan terus mengancam tumbuhnya inovasi software yang berakibat hilangnya kesempatan kerja dan berkurangnya penghasilan negara dari pajak. Meski tingkat pembajakan masih tinggi (Tempointeraktif, 2006).

Software Piracy bukan merupakan suatu masalah sampai munculnya personal computer, pernyataan ini didukung oleh keterbatasan hardware dan software yang dapat dipakai pada masa itu dan keterbatasan kepemilikan personal computer dan kualitas dari software hasil pembajakan tersebut tidak menurun. Hal ini diperparah dengan hadirnya internet yang memungkinkan proses download data tanpa takut dilacak ( Al-Rafee, 2002).

\section{ATITUDE}

Sikap pada perilaku membentuk penilaian perilaku (Cao \& Mokhtarian, 2005). Sikap dapat mencakup bermacam perasaan, seperti kepuasan secara umum, persepsi terhadap kualitas, dan bahkan respon emosional (Galleta et al., 2004). Menurut Fishbein dan Azjen (1975), sikap individual didefinisikan sebagai tingkat dimana individu menyukai atau tidak menyukai suatu obyek. Sedangkan menurut Malhotra dan Galleta (1999), sikap dapat didefinisikan sebagai pandangan yang positif maupun pandangan negatif dari seseorang pengguna secara individu terhadap suatu perilaku tertentu.

\section{SUBJECTIVE NORMS}

Subjective norms sebagai tingkat kepercayaan seseorang terhadap pendapat dari orang-orang di sekitarnya yang menyarankannya agar melakukan suatu perilaku (Fishbein \& Ajzen, 1975). Begitu juga menurut Himberg (1996) serta Pavlou dan Chai (2002), yang menyatakan bahwa Subjective norms adalah pengaruh dari keyakinan normatif seseorang bahwa orang lain menyetujui atau tidak menyetujui suatu perilaku tertentu atau persepsi seseorang bahwa orang-orang di sekitarnya yang penting baginya merasa tindakan tersebut harus dilakukan.

Ketika seseorang memutuskan untuk melakukan suatu atau tidak melakukan suatu tindakan, orang tersebut akan mempertimbangkan harapan dari orang lain yang dianggap penting baginya, seperti teman, rekan kerja, dan teman sekolah (Wu \& Liu, 2007). Jika seseorang memiliki pola subjective norms yang lebih positif terhadap pembajakan software, maka akan lebih cenderung memiliki niat 
Volume 5 No. 2

November 2017

untuk menggunakan software bajakan (Chen et al., 2009).

\section{PERCEIVED BEHAVIORAL CONTROL}

Perceived Behavioral Control menyatakan bahwa sikap menentukan keinginan untuk melakukan sesuatu, dan biasanya manusia selalu menitikberatkan pada pemikiran kepercayaan akan hasil yang dihasilkan oleh tingkah laku (sikap kepercayaan), kepercayaan tentang hasil wajar dan motivasi untuk dibandingkan hasil yang diinginkan (kepercayaan yang wajar). Perceived behavioral control mempengaruhi keinginan, tetapi juga dapat digunakan untuk mempekuat seseorang melakukan suatu hal (Cronan \& Al-Rafee, 2006). Perceived behavior control adalah persepsi konsumen apakah tindakan perilaku adalah dalam kendali mereka dan mencerminkan keyakinan mereka tentang akses ke sumber daya dan peluang yang diperlukan untuk memfasilitasi perilaku (Ajzen, 1991).

\section{MORAL OBLIGATION}

Menurut Beck dan Azjen (1991), moral obligation adalah prediktor signifikan yang baik untuk perilaku kecurangan atau pembentukan maksud untuk menipu. Setelah itu, Beck dan Ajzen (1991), menemukan bahwa moral obligation diberikan keuntungan yang sederhana dalam daya prediksi Theory of Planned Behavior yang ditambahkan 2 komponen moral yaitu moral obligation dan moral reasoning yang bertujuan untuk mengurangi perilaku tidak etis dan menghentikan siswa untuk melakukan perbuatan yang tidak etis (Trevor et al., 2007).

\section{PAST PIRACY BEHAVIOR}

Menurut Henk et al, (1997), past behavior merupakan pengalaman yang baik untuk melakukan peningkatan praktek secara bertahap dalam membuat suatu proses keputusan. Selain itu, Henk et al, (1997), mengharapkan dengan latihan peningkatan perceived behavioral control yang berhubungan langsung dengan perilaku, karena secara bertahap menjadi pengganti kontrol sebenarnya dengan kinerja yang memadai yaitu kemampuan dan keterampilan. Sehingga Henk et al, (1997), berpendapat bahwa dampak dari past behavior terhadap perilaku adalah batas dari persepsi desirabilita, norma sosial, kontrol dan niat untuk melaksanakan perilaku tersebut.

\section{INTENTION}

Menurut Malhotra dan Galleta (1999) intention merupakan pengukuran atau penilaian terhadap kemauan atau niat seseorang dalam melaksanakan suatu tindakan yang spesifik. Kemudian menurut Cao dan Mokhtarian (2005), niat perilaku mengukur seberapa keras seseorang bersedia untuk mencoba, atau besarnya niat dari usaha yang diharapkan dalam melakukan suatu tindakan. Selain itu, Cao dan Mokhtarian (2005) juga menyatakan bahwa semakin kuat niat perilaku individu, maka semakin besar juga kemungkinan individu tersebut untuk melakukan suatu tindakan.

\section{BEHAVIOR}

Menurut Moores et al. (2009), Behavior didefinisikan dalam hal kepatuhan hak cipta, atau sejauh mana seorang individu mempertahankan komputer pribadi yang tidak berlisensi atau bebas dari bajakan software. Menurut Ajzen (1991), perilaku dipandu oleh tiga faktor yaitu keyakinan tentang hasil kemungkinan perilaku dan 
evaluasi dari hasil (keyakinan perilaku), keyakinan tentang normatif harapan orang lain dan motivasi untuk mematuhi harapan (normatif keyakinan), dan keyakinan tentang keberadaan faktor yang dapat memfasilitasi atau menghambat perilaku kinerja dan kekuatan dianggap faktor ini (keyakinan kontrol).Menurut Fishbein dan Ajzen (1975), Ajzen (1991), mengakui bahwa behavior masal lalu dapat mempengaruhi behavior yang akan datang dan dapat menghasilkan feedback yang mempengaruhi sikap, persepsi dari normanorma sosial dan kontrol. Menurut Sheppard et al. (1988), mendukung pandangan meta analisis mencerminkan bahwa tindakan proses seleksi behavior yang melekat pada pencapaian tujuan cenderung meningkatkan prediksi behavior tertentu

Loyalitas mahasiswa pada umumnya memiliki sikap untuk melakukan pembajakan digital sehingga mahasiswa memiliki niat dalam melakukan pembajakan. Dapat diambil hipotesa bahwa semakin tinggi sikap pembajakan mahasiswa, maka semakin tinggi niat dalam melakukan pembajakan.

Sikap ataupun attitude juga bisa menganalisa niat seorang individu dalam melakukan suatu tindakan dalam pembajakan digital. Alasan mengapa bisa dijadikan analisa karena attitude bisa berubah menjadi sebuah persuasive ataupun yang bisa kita sebut sebagai rayuan dalam melakukan tindakan pembajakan. Individu dengan attitude yang berkoresponden dengan pembajakan lebih tinggi dan memungkinkan akan mempunyai niat yang tinggi untuk melakukan pembajakan pada materi digital. (Cronan \& Al-Rafee, 2008).
$\mathbf{H}_{1}$ : Adanya pengaruh attitude terhadap intenton dalam pembajakan digital (software).

Salah satu alasan seorang individu melakukan pembajakan adalah norma subjektifnya. Norma subjektif adalah persepsi seorang individu dalam tekanan sosial untuk melakukan atau tidak melakukan tingkah laku yang spesifik. Bertindaknya suatu tingkah laku tergantung pada orang-orang yang disekitarnya. Pembuktian telah menunjukkan norma subjektif mempengaruhi niat seorang individu. (Cronan \& Al-Rafee, 2008).

$\mathbf{H}_{2}$ : Adanya pengaruh subjective norms terhadap intention dalam pembajakan digital (software).

Perceived Behavioral Control adalah sebuah kesadaran akan mudah atau susahnya seorang individu dalam melakukan sebuah perilaku. Hal ini menujukkan seseorang akan melakukan pembajakan ataupun tidak walaupun norma subjektifnya memungkinkan. (Cronan \& Al-Rafee, 2008).

$\mathbf{H}_{3}$ : Adanya pengaruh perceived behavior control terhadap intention dalam pembajakan digital (software).

Moral Obligation adalah sebuah tuntutan dalam seorang individu untuk melakukan pemikiran untuk menanyakan pada dirinya apakah sebuah tindakan yang bersalah (pembajakan) akan dilakukan atau tidak. Moral Obligation menjadi penentu yang sangat besar dalam pembahasan yang ada (Cronan \& Al-Rafee, 2008).

$\mathbf{H}_{\mathbf{4}}$ : Adanya pengaruh moral obligation terhadap intention dalam melakukan pembajakan digital (software).

Past Piracy Behavior dikenal sebagai frekuensi terjadinya pembajakan digital pada masa lalu. Sikap pada masa lalu 
terhadap pembajakan mempunyai pengaruh terhadap sikap masa depannya. (Cronan \& Al-Rafee, 2008).

$\mathbf{H}_{5}$ : Adanya pengaruh past piracy behavior terhadap intention dalam melakukan pembajakan digital (software).
Intention adalah sesuatu mendahului yang perilaku, yang diasumsikan berada di bawah kehendak kontrol (Howard, 2005).

$\mathbf{H}_{\mathbf{6}}$ : Adanya pengaruh intention terhadap behavior dalam melakukan pembajakan digital (software).

Dari hipotesa-hipotesa di atas, dapat dibangun sebuah model penelitian seperti:






\section{METODE PENELITIAN}

Penelitian ini dirancang dalam bentuk kausal komparatif, yaitu tipe penelitian dengan karakteristik masalah berupa hubungan sebab akibat antara 2 variabel ataupun lebih yang meliputi variable independen dan variabel dependen, dengan tujuan untuk mengetahui pengaruh faktorfaktor yang mempengaruhi niat dalam melakukan pembajakan digital di kalangan mahasiswa batam.

Objek dalam penelitian ini adalah seluruh kampus yang tergabung dalam group

\section{HASIL DAN PEMBAHASAN}

Data yang diperoleh diolah dengan menggunakan SPSS versi 20. Pengaruh antara variable independen dengan variable dependen diukur dengan melihat tingkat signifikansi melalui uji hipotesis menggunakan analisa regresi linier
GICI Business School Batam yaitu STMIK GICI Batam, Akademi Akuntansi Permata Harapan, dan Akademi Bahasa Inggeris Permata Harapan Batam.

Metode sampling yang digunakan adalah purposive sampling. Metode purposive sampling adalah metode yang digunakan di mana responden hanya ditujukan kepada mahasiswa yang pernah melakukan pembajakan digital, sehingga total sample yang diperoleh sebanyak 100 responden. Sehingga hasil penelitian dapat dianggap mewakili populasi.

berganda dan analisa regresi linier sederhana.

Jika digambarkan dalam tabel, maka nilai hasil analisis data yang diperoleh dapat disajikan sebagai berikut: 
ISSN 2338-1523

E-ISSN 2541-576X

Volume 5 No. 2

November 2017

Uji Hipotesis Dalam Regresi Linier Berganda

\begin{tabular}{|c|c|c|c|c|c|}
\hline & Model & $\begin{array}{c}\text { Unstandardized } \\
\text { Coefficients }\end{array}$ & $\mathbf{T}$ & Sig. & Kesimpulan \\
\hline \multirow[t]{7}{*}{1} & Konstanta & 0.211 & 0.776 & 0.446 & \\
\hline & Attitude & 0.432 & 8.721 & 0.000 & H1: Diterima \\
\hline & Perceived Behavior & & & & \\
\hline & Control & 0.126 & 2.848 & 0.001 & H2: Diterima \\
\hline & Subjective Norms & 0.193 & 3.972 & 0.000 & H3: Diterima \\
\hline & Moral Obligation & -0.178 & -2.974 & 0.001 & H4: Diterima \\
\hline & Past Piracy Behavioral & 0.144 & 3.277 & 0.003 & H5: Diterima \\
\hline
\end{tabular}

Uji Hipotesis Dalam Regresi Linier Sederhana

\begin{tabular}{llcccl}
\hline & Model & $\begin{array}{c}\text { Unstandardized } \\
\text { Coefficients }\end{array}$ & T & Sig. & Kesimpulan \\
\hline 1 & Konstanta & 2.415 & 22.741 & 0.000 & \\
& Intention & -0.166 & -3.784 & 0.009 & H6: Diterima \\
\hline
\end{tabular}

Behav

JURSIMA

Jurnal Sistem Informasi dan Manajemen https://ejournal.giciku.ac.id/

STMIK GICI 


\section{SIMPULAN}

Pada hasil penelitian yang dilakukan pada survei terhadap 100 mahasiswa yang pernah melakukan pembajakan software di GICI Business Batam, penulis menemukan 5 faktor yang paling dominan mempengaruhi intention pada pembajakan software di kota Batam yaitu attitude, perceived behavioral control, subjective norms, moral obligation dan past piracy behavior. Penulis juga menemukan intention pada pembajakan software mempengaruhi behavior pada pembajakan software.

\section{DAFTAR PUSTAKA}

Ajzen, I. (1991). The theory of planned behavior. Organizational Behavior and Human Decision Processes 50, 179-211.

Albert-Miller, N., D. (1999). Consumer Misbehavior: Why People Buy Illicit Goods. The Journal of Consumer Marketing.

Al-Jabri, I., \& Abdul-Gader, A. (1997). Software Copyright Infringements: An Exploratory Study of the Effects of Individual and Peer Beliefs. Omega, International Journal of Management Science (25:3), pp. 335-344.

Al-Rafee, S. (2002). Digital piracy: Ethical decision making. Proquest Information and Learning.
Antonio, R., A. (2002). The Europen Software Piracy: An Empirical Application. Department of Economics, University of Southern Denmark.

Banerjee, D., Cronan, T. P., \& Jones, T. W. (1998). Modeling IT ethics: A study in situtional ethics. MIS Quarterly, 22(1), 31-60.

Bagozzi, R. P., Baumgartner, H. \& Yi, Y. (1991). Coupon Usage and The Theory of Reasoned Action. Advances in Consumer Research.

Cao, X., \& Mokhtarian, P. L. (2005). The intended and actual adoption of online purchasing: A brief review of recent literature. Research on Eshopping Intention and Adoption, 7, 1-60.

Chang, M., K. (1998). Predicting Unetchical Behavior: A Comparasion of The Theory of Reasoned Action and The Theory of Planned Behavior. Journal of Business Ethics 17: 1825-1834.

Chau, P. Y. K. \& Hu, P. J., (2002). Examining a Model of Information Technology Acceptance by Individual Professionals: An Exploratory Study. Journal of Management Information Systems, 184, 191230

Cheng, H. K., Sims, R. R., \& Teegen, H. (1997). To Purchase or To Pirate https://ejournal.giciku.ac.id/ STMIK GICI 
ISSN 2338-1523

E-ISSN 2541-576X

Volume 5 No. 2

November 2017

Software: An Emperical Study.Journal of Management Information System.

Cronan, T. P., \& Al-Rafee, S. (2008). Factors that Influence the Intention to Pirate Software and Media. Journal of Business Ethics , 78 (4), 527-545.

Cronan, T. P., \& Al-Rafee, S. (2006). Digital piracy: factors that influence attitude toward behavior. Journal of Business Ethics 63(3), 237-59.

Daniel, J. O'Kefee \& Jesse, G. Delia. (2003). Construct Differentation and The Relationship of Attitudes and Behavioral Intention.

Eining, M. M, and Christensen, A. L., (1991). Factors Influencing Software Piracy: Implications for Accountants.

Fishbein, M. \& Ajzen, I. (1985). A Field Application of The Fishbein and Ajzen Intention Model. The Journal of Social Phsycology, 126(1), 135-136.

Flannery, L. Brenda. \& May, R. Douglas. (2000). Enviroment Ethical Decision Making in The U.S. Metal-Finishing Industry. Academy of Management Journal : 4, 642662.

Fritzsche, D., J. \& Becker, H. (1984). Linking Management Behavior to Ethical Philosophy-An Empirical Investigation. Academy of Management Jounal 27, 11675.

JURSIMA

Jurnal Sistem Informasi dan Manajemen
Galleta, D., Henry, R., McCoy, S., \& Polak, P. (2004). Web site delays: How tolerant are users?. Journal of the Association for Information Systems, 5(1), 1-28.

Ghozali, I. (2001). Aplikasi analisis multivariate dengan program SPSS. Semarang: Badan Penerbit Universitas Diponegoro.

Henk, A., Theo, P. \& Herman, S. (1997). Physical Exercise Habit: on The Conceptualization and Formation of Habitual Health Behaviours. Health Education Research. Vol 12 no.13 P.363374.

Henle, A. Christine., Reeve, L. Charlie., \& Pitts, E. Virgina. (2009). Stealing Time at Work: Attitudes, Social Pressure, and Perceived Control as Predictors of Time Theft. Journal of Business Ethics. 94:53-67.

Himberg, C. (1996). Video Technology and The Subjective Norms, Perceived Behavioral Control and Attitude Toward Physical Activity of Middle School Students: Does P.E.TV make a Difference?

Howard, F. Buchan. (2005). Ethical Decision Making in The Public Accounting Profession: An Extension of Ajzen's Theory of Planned Behavior. Journal of Business Ethics 61: 165-181.

Huang, M., Zhu, H., \& Liu, M. (2007). Why Do Chinese User https://ejournal.giciku.ac.id/ STMIK GICI 
Volume 5 No. 2

November 2017

Use Pirated Software: An Integrative Perspective.

Indriantoro, N., \& Supomo, B. (1999). Metodologi penelitian bisnis untuk akuntansi dan manajemen. Yogyakarata: BPFE

Lin, T., C., Hsu, M., H., Kuo, F., Y., \& Sun, P., C. (1999). An Intention Model-Based Study of Software Piracy.

Malhotra, Y., \& Galleta, D. F. (1999). Extending the technology acceptance model to account for social influence: Theoretical Bases and Empirical Validation. Hawaii International Conference on System Sciences, 1-14.

Mathieson, K. (1991). Predicting User Intentions: Comparing the Technology Acceptance Model with the Theory of Planned Behavior. Information Systems Research 2, 173-191.

McDonald, G. \& Roberts, C. (1994). Product Piracy: The Problem That Will not Go Away. The Journal of Product and Brand Management.

Mei, F., C., Ching, T., P., \& Ming, C., P. (2009). The Joint Moderating Impact of Moral Intensity and Moral Judgment on Consumer's Use Intention of Pirated Software.

Moores, T. Trevor., Nill, A., \& Rothenberger, A. Marcus. (2009). Knowledge of Software Piracy As An Antecedent To Reducing Pirating Behavior..
Nikos, L, D., Chatzisarantis. \& Stuart, J. H., Biddle. (1996). Functional Signifiance of Psychological Variables that are Icluded in The Theory of Planned Behaviour: SelfDetermination Theory Approach to The Study of Attitudes, Subjective Norms, Perceptions of Control and Intentions. School of Education, University of Exeter, $U K$.

Pavlou, P. \& Chai, L. (2002) What drives electronic commerce across cultures? A crosscultural empirical investigation of the theory of planned behavior. Journal of Electronic Commerce Research 3(4): 240253.

Peace, A.G., Galleta, D., F., \& Thong, J., Y., L. (2003). Software Piracy in the Workplace. Journal of Management Information Systems.

Phau, I. \& Teah, M. (2009). The Influence of Personality Factors on Attitude Towards Counterfeiting of Luxury Brands and Purchase Intention.

Ramdhani, N. (2007). Model Perilaku Penggunaan IT "NR2007" Pengembangan dari Technology Acceptance Model (TAM).

Randall, D. \& A. Gibson. (1991). Ethical Decision Making in The Medical Profession: An Application of The Theory 
ISSN 2338-1523

E-ISSN 2541-576X

Volume 5 No. 2

November 2017

Planned Behavior. Journal of Business Ethics 10: 111-122.

Richard, J., B., Derek, N., \& Christoper, S. (1984). Understanding Seat Belt use: a Test of Bentler and Speckart's Extension of The Theory of Reasoned Action. European Journal of Social Psychology.

Sheppard, B. H., Hartwick, J., \& Warshaw. P., R. (1988). The Theory of Reasoned Action: A Meta- Analysis of Past Research with Recommendations for Modifications and Future Research. Journal of Consumer Research 15, 325343.

Shen, D., Laffey, J., Lin, Y., \& Huang, X. (2006). Social influence for perceived usefulness and ease-of-use of course delivery systems. Journals of Interactive Online Learning, 5(3), 270-282.

Simpson, P,. M., Banerjee, D., \& Simpson, C., L., Jr. (1994). Softlining: A Model of Motivating Factors. Journal of Business Ethics. 13: 431-438.

Straub, D. \& Collins, R. (1990). Key Information Liability Issues Facing Managers: Software Piracy, Proprietary Databases, and Individual Right to Privacy. MIS Quarterly, 143156.

Tan, B. (2002). Understanding Consumer Ethical Decision Making With Respect to Purchase of Piranted Software.

Journal of Consumer Marketing. 96-111.

Thong, Y,. L. James. \& Yap, S, Chee. (1998). Testing on Ethical Decision Making Theory: The case of Softlifting. Journal of Management Information Systems: 1, 213237.

Trevol, S., H., Matthew, J., M., Cynthia, J., F. \& Donald, D., C. (2007). The Theory of Planned Behavior as a Model of Academic Dishonesty in Engineering and Humanities Undergraduates.

Wu, J. \& Liu, D. (2007). The effects of trust and enjoyment on intention to play online games. Journal of Electronic Commerce Research, 8(2), 128-140.

Yang, P., Zhang, L., Hong, G., Nasiri, L., S., Baum, A., B., Huang, L., H. \& King, D., M. (2007). Differences Between Collection 4 and 5 MODIS Ice Cloud Optical Microphysical Products and Their Impact on Radiative Forcing Simulations.IEEE

Transactions on Geoscience and Remote Sensing. vol. 45, NO. 9 